ICU admission rate and in-hospital mortality rate were not different between the two groups during the observation. This result was consistent in the sensitivity analysis where same analysis was performed in the post-matched population.

Thirty-four cases of ADRs of TMP-SMX occurred, with an incidence rate $(95 \% \mathrm{Cl})$ of 24.2 (17.3-33.0) per 100 person-year. There were two cases of serious ADR (one pancytopenia and one Steven's Johnson syndrome) but they all recovered shortly after the discontinuation of TMP-SMX. The number needed to harm (NNH) of serious ADR was 109 whereas the number needed to treat (NNT) to prevent one case of PCP in the whole population was 52 .

Conclusions: In patients with rheumatic disease receiving prolonged, high-dose steroid treatment, TMP-SMX prophylaxis significantly lower the incidence of PCP with favorable safety.

References:

[1] Stern A, Green H, Paul M, Vidal L, Leibovici L. Prophylaxis for Pneumocystis pneumonia (PCP) in non-HIV immunocompromised patients. The Cochrane database of systematic reviews. 2014(10):CD005590.

Disclosure of Interest: None declared

DOI: 10.1136/annrheumdis-2017-eular.2803

\section{OP0078 THE LONG TERM PROGNOSTIC SIGNIFICANCE OF PULMONARY HYPERTENSION IN SARCOIDOSIS - A BIG DATA ANALYSIS}

S. Tiosano ${ }^{1,2}$, O. Gendelman ${ }^{1,2}$, A. Watad ${ }^{1,2}$, D. Comaneshter ${ }^{3}$, A. Cohen ${ }^{3,4}$ H. Amital 1,2. 'Internal Medicine 'B', Sheba Medical Center, Ramat-Gan; ${ }^{2}$ Sackler School of Medicine, Tel-Aviv University; ${ }^{3}$ Chief physician's office, Clalit Health Services, Tel-Aviv; ${ }^{4}$ Siaal Research Center for Family Medicine and Primary Care, Faculty of Health Sciences, Ben Gurion University of the Negev, Beer Sheva, Israel

Background: Sarcoidosis is a multisystem, chronic, progressive, granulomatous disease. Sarcoidosis-associated pulmonary hypertension is well described, but not common complication of sarcoidosis ${ }^{1}$. In small scale studies, it has been previously described as a manifestation of advanced disease and was found to be associated with increased morbidity and mortality ${ }^{2}$. Previous studies have shown that treatment may be safe and improve pulmonary hemodynamics in sarcoidosisassociated pulmonary hypertension ${ }^{3,4}$. However, big data analyses regarding the exact magnitude and prognosis of sarcoidosis-associated pulmonary hypertension are lacking.

Objectives: To assess the long-term prognostic significance of sarcoidosisassociated pulmonary hypertension using a big data registry with a 15-year follow-up period.

Methods: Utilizing the medical records of Clalit Health Services, the largest $\mathrm{HMO}$ in Israel, we extracted a cohort consisted of sarcoidosis patients along with their age-and-sex matched controls. Dates of registration in the medical records of sarcoidosis, pulmonary hypertension and death, as well as anthropometric information and medical comorbidities were extracted from the database. To compare the distribution of variables across the cohort strata, univariate analysis was performed using Chi-square and student t-test. Multivariate analysis using a logistic regression model was used to find variables associated with pulmonary hypertension. Survival analysis using cox proportional hazards method and log-rank test was performed to find variables associated with increased risk of all-cause mortality.

Results: The cohort included 3,993 sarcoidosis patients and 19,856 ageand-sex matched controls. The mean age of both groups was 56 , and both consisted about $63 \%$ females. Pulmonary hypertension was observed among 269 sarcoidosis patients $(6.74 \%)$ vs. 400 controls $(2.01 \%), p<0.001$. In multivariate analysis, sarcoidosis was found to be independently associated with diagnosis of pulmonary hypertension (OR 3.09, 95\% Cl 2.6-3.67). After more than 15 years of follow-up, $710(17.8 \%)$ of the sarcoidosis patients had died, compared to $2121(10.7 \%)$ of the controls $(p<0.001)$. In multivariate survival analysis, both sarcoidosis and pulmonary hypertension were found to be significantly associated with increased risk to all-cause mortality (HR 1.83, 95\% Cl 1.66-2.02 and HR $2.32,95 \% \mathrm{Cl} 2.05-2.63$, respectively).

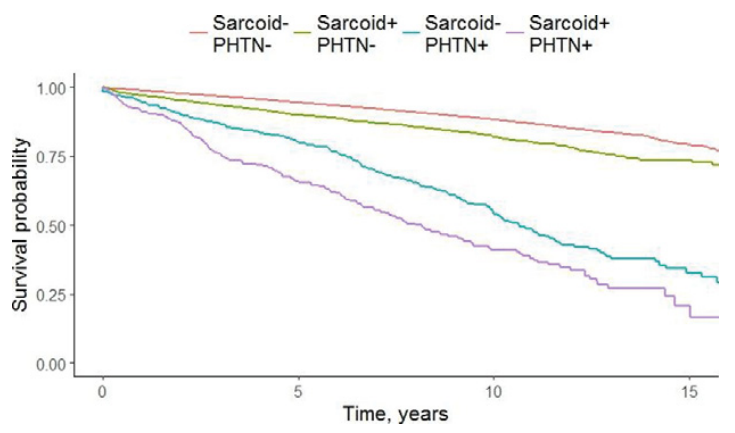

Conclusions: Sarcoidosis-associated pulmonary hypertension is associated with poor prognosis. Proper screening methods are recommended to assess whether early identification and treatment may improve life expectancy.
References:

[1] Baughman, R. P., Culver, D. A. \& Judson, M. A. A Concise Review of Pulmonary Sarcoidosis. Am. J. Respir. Crit. Care Med. 183, 573-581 (2011).

[2] Baughman, R. P., Engel, P. J., Taylor, L. \& Lower, E. E. Survival in SarcoidosisAssociated Pulmonary Hypertension. Chest 138, 1078-1085 (2010).

[3] Baughman, R. P. et al. Bosentan for Sarcoidosis-Associated Pulmonary Hypertension. Chest 145, 810-817 (2014).

[4] Keir, G. J. et al. Treatment of sarcoidosis-associated pulmonary hypertension: A single centre retrospective experience using targeted therapies. Sarcoidosis Vasc. Diffuse Lung Dis. 31, 82-90 (2014).

Disclosure of Interest: None declared

DOI: 10.1136/annrheumdis-2017-eular.4464

\section{OP0079 BODY FAT PERCENTAGE AND WAIST CIRCUMFERENCE WERE ASSOCIATED WITH THE DEVELOPMENT OF RHEUMATOID ARTHRITIS - A DANISH FOLLOW-UP STUDY}

A. Linauskas $^{1}$, A.L. de Thurah $^{1}$, K. Overvad ${ }^{2}$, M.B. Johansen ${ }^{3}$, K. Stengaard-Pedersen ${ }^{1}$. ${ }^{1}$ Department of Rheumatology, Aarhus University Hospital; ${ }^{2}$ Depatment of Public Health, Section of Epidemiology, Aarhus University, Aarhus; ${ }^{3}$ Unit of Clinical Biostatistics, Aalborg Univeristy Hospital, Aalborg, Denmark

Background: Several studies have investigated the association between overweight and the development of rheumatoid arthritis (RA) and have come out with conflicting results. Body Mass Index (BMI) has been the preferred surrogate measure for overweight in these studies. However, BMI correlates only modestly with total amount of body fat and does not reflect fat distribution.

Objectives: To investigate the association between BMI, waist circumference, bio-impedance-derived total body fat percentage and the incidence of RA.

Methods: A population-based cohort study conducted within the Danish Diet, Cancer and Health cohort, which included individuals aged 50 to 64 years at the recruitment in the period between 1993 and 1997. Body fat composition measurements and data on lifestyle factors were collected at the enrolment into the cohort. The participants who subsequently developed RA were identified via linkage to The Danish National Patient Registry. The participants were followed until development of RA, death, loss to follow-up or October 2016, whichever came first. Data were analyzed by Cox proportional hazards regression model with delayed entry and age as the underlying time variable. Analyses were stratified by gender. Cox regression analyses with restricted cubic spline were carried out to elucidate the dose-response association between anthropometric measures and risk of RA. Smoking, socio-economic status, alcohol consumption, physical activity and intake of $n-3$ fatty acids were included in multivariate analyses as potential confounders.

Table 1. Cox proportional hazard ratios for association between body composition measurements and incidence of RA

\begin{tabular}{|c|c|c|}
\hline \multirow[t]{2}{*}{ Variable } & \multicolumn{2}{|c|}{$\begin{array}{l}\text { Hazard ratio (95\% confidence interval)) } \\
\text { Multivariable adjusted }{ }^{*}\end{array}$} \\
\hline & Men & Women \\
\hline $\mathrm{BMI}<18.5 \mathrm{~kg} / \mathrm{m}^{2}$ & $\mathrm{~N} / \mathrm{A}$ & $0.86(0.21-3.48)$ \\
\hline BMI $18.5-24.99 \mathrm{~kg} / \mathrm{m}^{2}$ & 1 (ref) & 1 (ref) \\
\hline BMI $25-29.99 \mathrm{~kg} / \mathrm{m}^{2}$ & $0.83(0.55-1.24)$ & $1.48(1.14-1.91)$ \\
\hline $\mathrm{BMI}>30 \mathrm{~kg} / \mathrm{m}^{2}$ & $0.69(0.37-1.30)$ & $1.54(1.09-2.17)$ \\
\hline \multicolumn{3}{|c|}{ Abdominal obesity (waist circumference $>102 \mathrm{~cm}$ for men, $>88 \mathrm{~cm}$ for women) } \\
\hline No & 1 (ref) & 1 (ref) \\
\hline \multirow[t]{3}{*}{ Yes } & $1.16(0.75-1.80)$ & $1.24(0.96-1.61)$ \\
\hline & \multicolumn{2}{|c|}{$\begin{array}{c}\text { Hazard ratio (95\% confidence interval) } \\
\text { per } 1 \% \text { increment of body fat } \\
\text { Multivariable adjusted }\end{array}$} \\
\hline & Men & Women \\
\hline Fat percentage & $0.99(0.96-1.03)$ & $1.03(1.01-1.05)$ \\
\hline
\end{tabular}

${ }^{*}$ Adjusted for age, smoking status, total tobacco consumption (g/day), smoking duration, alcohol consumption ( $\mathrm{g} /$ day), socio-economic status, physical activity (Metabolic Equivalent of Task, MET), total intake of $n-3$ fatty acids.

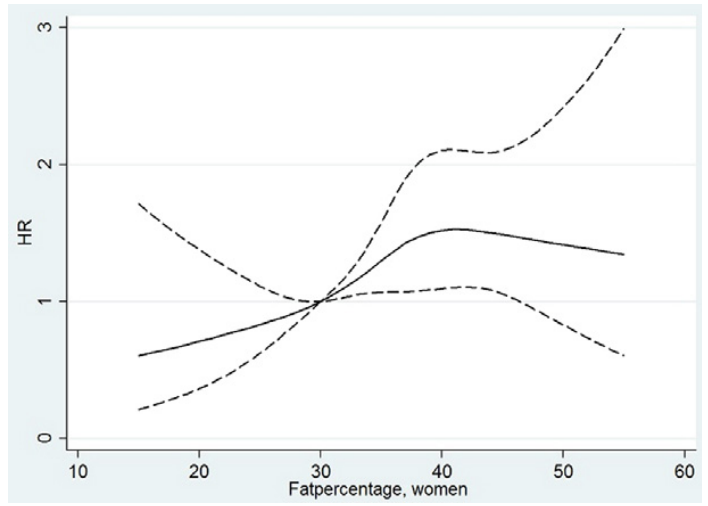


Results: Data were available on 54284 subjects (52\% female). During follow-up (median 21 years), 283 women and 110 men developed RA. The median (IQR) time to onset of RA was 7 (4-11) years. The adjusted hazard ratio's (HR) for developing RA are presented in Table 1. Restricted cubic spline analysis of body fat percentage displayed a positive slope in women (Image). There was no linear association between amount of fat and incidence of RA among men.

Conclusions: Overweight and obesity, defined by BMI, abdominal obesity and higher body fat percentage, especially above $30 \%$, were in women associated with a higher risk for the development of RA. In men the associations were not consistent.

Acknowledgements: The Danish Rheumatism Association, The Danish Heart Foundation, Central Denmark Region, North Denmark Regional Hospital, Scandinavian Rheumatology Research Foundation

Disclosure of Interest: None declared

DOI: 10.1136/annrheumdis-2017-eular.1526

\section{OP0080 RISK OF AUTISM SPECTRUM DISORDER IN CHILDREN BORN TO MOTHERS WITH SYSTEMIC LUPUS ERYTHEMATOSUS AND RHEUMATOID ARTHRITIS IN TAIWAN}

P.-H. Tsai, C.-F. Kuo, L.-H. Huang, S.-F. Luo. Division of Rheumatology, Allergy and Immunology, Chang Gung Memorial Hospital, Taoyuan, Taiwan, Province of China

Background: There is emerging evidence suggesting that offspring born to patients with rheumatic diseases has higher risk of neuropsychiatric diseases. Previous data from Quebec showed children born to women with SLE have an increased risk of autism spectrum disorder (ASD) but data regarding risk of ASD in offspring of mothers with systemic lupus erythematosus (SLE) or rheumatoid arthritis (RA) mothers have not been reported in other population.

Objectives: We aimed to examine whether offspring of mothers with SLE and RA in Taiwan has a higher risk of developing ASD using data from a linkage between National Health Insurance (NHI) database and National Birth Registry in Taiwan. Methods: We established a birth cohort of all live-births between 2001 and 2012 in Taiwan established using the National Health Insurance database and the National Birth Registry. Children born to mothers with SLE or RA were identified and matched up to 8 controls by maternal age, 1-minute Apgar score, 5-minute Apgar score, mode of delivery, sex of child, gestational age, birth weight, socioeconomic status (place of residence, income level, occupation). A marginal Cox proportional hazard models were used to estimate the relative risk (RR; $95 \%$ confidence interval $[\mathrm{Cl}]$ ) for ASD in newborns with affected mothers.

Results: Of $1,893,244$ newborns, $0.08 \%(n=1,594)$ were born to mothers with SLE (mean age $30.43 \pm 4.37$ years old) and $0.04 \%(n=673)$ were born to mothers with RA ( $31.97 \pm 4.51$ years old). Overall, 5 of $673(0.74 \%)$ RA offspring developed ASD, 7 of $1594(0.44 \%)$ SLE offspring developed ASD and 10,631 of 1,893,244 $(0.56 \%)$ all infants developed ASD. The incidence of ASD was $140.39(95 \% \mathrm{Cl}$, 45.58-327.62) per 100,000 person-years for RA group, 76.19 (95\% Cl, 30.63156.97) per 100,000 person-years for SLE group, 89.85 (95\% Cl, 88.15-91.57) per 100,000 person-years for non-RA group and 89.87 (95\% Cl, 88.17-91.60) per 100,000 person-years for non-SLE group. The children born to RA and SLE mothers did not have higher risk of ASD with a HR $(95 \% \mathrm{Cl})$ of $1.42(0.60-3.40)$ and $0.76(0.36-1.59)$ for ASD, respectively.

Conclusions: Children born to women with SLE and RA do not have higher risk of developing ASD.

References:

[1] Lahita, R.G., Systemic lupus erythematosus: learning disability in the male offspring of female patients and relationship to laterality. Psychoneuroendocrinology, 1988. 13(5): p. 385-96.

[2] Vinet, E., et al., Increased Risk of Autism Spectrum Disorders in Children Born to Women With Systemic Lupus Erythematosus: Results From a Large Population-Based Cohort. Arthritis Rheumatol, 2015. 67(12): p. 3201-8.

Disclosure of Interest: None declared

DOI: 10.1136/annrheumdis-2017-eular.2882

\section{WEDNESDAY, 14 JUNE 2017}

\section{Scleroderma, myositis and related ethology}

\section{OP0081 PAN-PPAR AGONIST IVA337 IS EFFECTIVE IN THE PREVENTION OF EXPERIMENTAL LUNG FIBROSIS AND PULMONARY HYPERTENSION}

J. Avouac ${ }^{1}$, I. Konstantinova ${ }^{2}$, C. Guignabert ${ }^{3}$, J. Sadoine ${ }^{4}$, G. Thomas $^{5}$ S. Pezet ${ }^{5}$, A. Cauvet ${ }^{5}$, L. Tu ${ }^{3}$, J.M. Luccarini ${ }^{2}$, J.L. Junien ${ }^{2}$, P. Broqua ${ }^{2}$, Y. Allanore ${ }^{1} .{ }^{1}$ Rheumatology $A$ and INSERMU1016, Paris Descartes University, Cochin Hospital, Paris; ${ }^{2}$ Inventiva, Daix; ${ }^{3}$ INSERM UMR s 999, le Plessis Robinson; ${ }^{4}$ Université Paris Descartes, Montrouge; ${ }^{5}$ INSERM U1016, Paris, France

Background: Peroxisome proliferator-activated receptors (PPARs) are nuclear receptors known to modulate fibrosis. The pan-PPAR agonist IVA337 recently demonstrated efficacy in prevention and treatment of experimental skin fibrosis [1].
Objectives: Our objective was to evaluate the antifibrotic effects of IVA337 in preclinical mouse models of pulmonary fibrosis and related pulmonary hypertension $(\mathrm{PH})$.

Methods: IVA337 has been evaluated in the mouse model of bleomycin-induced pulmonary fibrosis and in Fra-2 transgenic mice, this latter being characterized by non-specific interstitial pneumonia and severe vascular remodeling of pulmonary arteries leading to PH. Mice received 2 doses of IVA337 (30 mg/kg or $100 \mathrm{mg} / \mathrm{kg}$ ) or vehicle administered by daily oral gavage up to 4 weeks.

Results: Both $30 \mathrm{mg} / \mathrm{kg}$ and $100 \mathrm{mg} / \mathrm{kg}$ doses of IVA337 were well tolerated in all mouse models.

IVA337 demonstrated at a dose of $100 \mathrm{mg} / \mathrm{kg}$ a marked protection from the development of lung fibrosis induced by bleomycin compared to mice receiving $30 \mathrm{mg} / \mathrm{kg}$ of IVA337 or vehicle. Indeed, IVA337 (100 mg/kg) strongly reduced by $61 \%$ and $28 \%$ tissue density on histological measurements and total lung hydroxyproline concentrations, respectively, as compared to vehicle. IVA337 at $100 \mathrm{mg} / \mathrm{kg}$ also significantly decreased col1, col3 and fibronectin in lesional lungs. Similarly, Fra-2 transgenic mice treated with $100 \mathrm{mg} / \mathrm{kg}$ of IVA337 displayed reduced lung density ( $20 \%$ vs. vehicle) and significant increase of functional residual capacity ( $30 \%$ vs. vehicle) when assessed by chest micro-CT imaging. These results were emphasized by a $50 \%$ reduction of the Ascroft fibrosis score (Figure $1 \mathrm{~A}$ ) and by a $48 \%$ reduction of hydroxyproline concentrations upon IVA337 $(100 \mathrm{mg} / \mathrm{kg})$ compared to vehicle treated mice.

Successful targeting of the TGF-b signaling axis was observed in both mouse models upon treatment with $100 \mathrm{mg} / \mathrm{kg}$ of IVA337. $100 \mathrm{mg} / \mathrm{kg}$ IVA337 also significantly reduced $T$ cell and $B$ cell infiltration in lesional lungs of Fra-2 transgenic mice.

Regarding vessel remodeling and related pulmonary hypertension, treatment with $100 \mathrm{mg} / \mathrm{kg}$ of IVA337 led to a substantial attenuation of right ventricular systolic pressure and right ventricular hypertrophy compared to mice receiving the vehicle (Figure 1B and $1 \mathrm{C}$ ). Furthermore, IVA337 given at $100 \mathrm{mg} / \mathrm{kg}$ markedly reduced medial wall thickness (Figure 1D) and the number of muscularized distal pulmonary arteries.

In vitro in primary human lung fibroblasts, IVA337 inhibited in a dose-dependent manner TGF $\beta$-mediated fibroblasts to myofibroblasts transition and PDGFmediated proliferation.

A
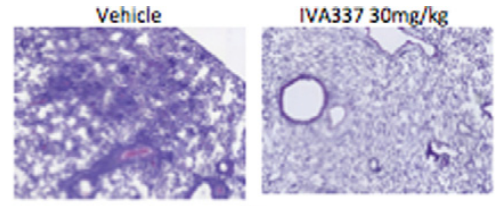
IVA337 $100 \mathrm{mg} / \mathrm{kg}$

B
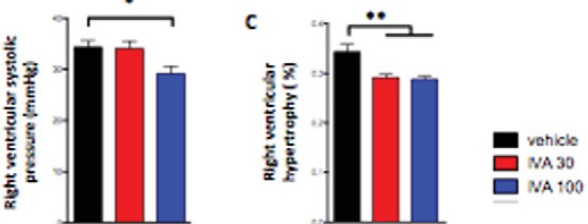
Vehicle IVA337 $30 \mathrm{mg} / \mathrm{kg}$ IVA337 $100 \mathrm{mg} / \mathrm{kg}$

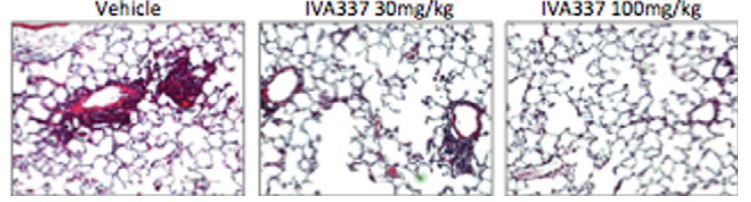

Figure 1

Conclusions: We demonstrate that treatment with $100 \mathrm{mg} / \mathrm{kg}$ IVA337 prevents lung fibrosis in two complementary animal models and substantially attenuates $\mathrm{PH}$ in the Fra-2 mouse model. These findings confirm that the pan-PPAR agonist IVA337 is an appealing therapeutic candidate for systemic sclerosis both, for skin and key cardiovascular complications.

References:

[1] Ruzehaji et al, Ann Rheum Dis 2016;75(12):2175-2183.

Disclosure of Interest: J. Avouac: None declared, I. Konstantinova Employee of: INVENTIVA, C. Guignabert: None declared, J. Sadoine: None declared, G. Thomas: None declared, S. Pezet: None declared, A. Cauvet: None declared, L. Tu: None declared, J. M. Luccarini Employee of: INVENTIVA, J. L. Junien Consultant for: INVENTIVA, P. Broqua Employee of: INVENTIVA, Y. Allanore

Grant/research support from: Inventiva

DOI: 10.1136/annrheumdis-2017-eular.3805 